\title{
Femur fracture repair of a tiger cub (Panthera tigris tigris) suffering from nutritional secondary hyperparathyroidism and osteopenia
}

\author{
Charles Boucher, Gareth Zeiler
}

Companion Animal Clinical Studies, University of Pretoria, Pretoria, Gauteng, South Africa

\section{Correspondence to} Dr Charles Boucher, charlie.boucher@up.ac.za

\begin{abstract}
SUMMARY
A five-month old tiger (Panthera tigris tigris) presented for an acute-onset pelvic limb lameness workup. The cub had been fed a meat-only diet. Radiology revealed severe generalised osteopenia, pathological fractures of the pelvis and proximal right femur. The history, clinical presentation and pathognomonic radiographic findings were consistent with nutritional secondary hyperparathyroidism. The cub was initially treated conservatively by dietary management (whole chicken supplemented with calcium-multivitamin powder). Fourteen day follow-up radiographs revealed increased bone density, healing pelvic fractures and callus formation around the displaced femoral fracture fragments. Despite the osteopenia, the femoral cortices were considered dense enough to allow internal fixation using a locking plate-rod combination. Fracture reduction was complicated by extensive callus formation and muscle atrophy. Follow-up radiography on day 63 revealed excellent secondary bone healing and improved bone density. The cub was discharged into the owner's care and has reportedly made a full recovery.
\end{abstract}

\section{BACKGROUND}

Tigers are regarded as exotic species in South Africa and unlike the strict controls and regulations imposed on the acquisition and possession of indigenous species, permits are not currently required for these large felids. This has led to an increased demand for tigers within the game farming industry in South Africa (Coetzee 2011). The owners are often unaware of the dietary requirements of these animals, especially during the growth phase and they are frequently fed on meat-only diets. In the wild, these animals would feed on whole carcases and obtain a source of calcium through the digestion of bones.

Young, captive, fast-growing carnivores fed an exclusive meat diet deficient in calcium or diets with an inappropriate calcium:phosphorus ratio (ideal 2:1) are prone to developing nutritional secondary hyperparathyroidism (NSH) (Barr 2006). Symptoms of NSH were described in the early 1800s in zoo-reared lion cubs well before the recognition of this metabolic bone disease (Pederson 1983). Decreased calcium intake and/or increased phosphorus intake (meat-only diets) stimulates the parathyroid gland to release parathyroid hormone. This stimulates calcium resorption from bone to maintain physiological normal plasma calcium and phosphorus levels. This pathological process, however, comes at the expense of progressive demineralisation leading to osteopenia (Krook and Whalen 2010).

Pathological fractures are a common complication associated with NSH and have been reported in a number of species (Barr 2006). The pelvis is typically affected and fractures with collapse of the pelvic girdle are common (Roberts 2004). Fractures of the long bones are often compression fractures with telescoping of the bone fragments (Herz and Kirberger 2004). Greenstick fractures of the appendicular skeleton are also commonly seen (Dimopoulou and others 2010).

NSH is diagnosed a lot less frequently in domestic animals since the advent of balanced commercial feline and canine food. The veterinary literature on feline NSH is limited (Dimopoulou and others 2010) with very few recent publications. Tomsa and others (1999) described case series of six cats with NSH. Pathological fractures of long bones, scapulae, pelvis, nasal bones and the spine were all documented in this case series. Two of these cats were euthanased due to severe neurological deficits secondary to spinal fractures. The remaining cases were all managed medically, which included a balanced diet and cage rest. More recently Dimopoulou and others (2010) reported on two cats with NSH. The first of these cats had multiple bilateral fractures of the femur, tibia, fibula and pelvis. This cat was euthanased due to its inability to ambulate, urinate or defecate. The other cat in this report had folding fractures of the left femur and pelvis. This cat responded well to medical treatment, a balanced diet and cage rest and had no visible signs of lameness after three weeks (Dimopoulou and others 2010) . Lamb reported on the radiographic findings of osteopenic bone in 1990. One of the elderly cats in his report sustained a long oblique fracture which was surgically repaired with an intramedullary pin and cerclage wire. This appears to be the only report of surgical intervention in domestic cats with pathological fractures secondary to osteopenia (Lamb 1990).

To the authors' knowledge, there have not been any surgical reports on the repair of fractures in osteopenic bone in large felids. This case report describes some of the challenges encountered during the surgical repair of a pathological fracture of the proximal osteopenic femoral diaphysis in a tiger cub with secondary nutritional hyperparathyroidism. 


\section{CASE PRESENTATION}

A five-month-old male Bengal tiger (Panthera tigris tigris) cub presented to the Onderstepoort Veterinary Academic Hospital $(\mathrm{OVAH})$ for evaluation of an acute-onset non-weightbearing pelvic limb lameness. He was parent-reared until the age of four months after which he was weaned and sold to a new owner. He was fed a meat-only diet and was severely underweight $(11.95 \mathrm{~kg})$ for his age and emaciated.

\section{INVESTIGATIONS}

On initial presentation (day 1), the cub was sedated with a combination of $0.2 \mathrm{mg} / \mathrm{kg}$ midazolam (Dormicum 0.5 per cent; Roche Products, Johannesburg, South Africa) and $0.2 \mathrm{mg} / \mathrm{kg}$ butorphanol (Torbugesic; Fort Dodge Animal Health, Isando, Gauteng, 1600, South Africa) injected into the lumbar muscle for physical examination, blood sampling and radiography. The cub was injected with a single subcutaneous dose of $0.2 \mathrm{mg} / \mathrm{kg}$ meloxicam (Mobic; Ingelheim Pharmaceuticals, Johannesburg, South Africa) before recovery from the diagnostic imaging.

The pelvis and pelvic limb radiographs revealed severe osteopenia of all the imaged bones. The right ilium and left ischium had non-displaced compression fractures with collapse of the pelvic canal. There was a comminuted proximal right femoral diaphyseal fracture with some telescoping of the fragments and moderate-to-severe soft tissue swelling of the area (Fig 1).

A presumptive diagnosis of NSH with pathological fractures was made based on history and presentation and confirmed by pathognomonic radiographic findings.

\section{TREATMENT}

The initial investigation revealed generalised osteopenia and femoral fracture fragments unable to support surgical stabilisation. The cub was then referred to the veterinary hospital of the National Zoological Gardens of South Africa (NZGSA) for nutritional and medical management of the condition.

The cub was hospitalised and injected intramuscularly with $1.2 \mathrm{ml}$ of a multivitamin/multimineral/amino acid supplement (Kyroligo, Kyron Laboratories (Pty) Ltd, Johannesburg, Gauteng, 2094, South Africa), thus providing, among other things, an additional 30,000 international units (IU) of vitamin
$\mathrm{D}_{3}$. He was fed a diet consisting of one whole uncooked chicken (approximately $1.2 \mathrm{~kg}$ ) supplemented with $45 \mathrm{~g}$ of calcium-multivitamin powder (Predator Supplement, Healthtech Laboratories (Pty) Ltd, Midrand, Gauteng, 1686, South Africa) per day. Analgesics were administered based on behavioural changes and on a decrease in appetite. It was difficult to monitor his condition due to his shyness and aggression, but the cub appeared to make good progress in terms of mobility and appetite, thus no further analgesics were administered at this stage of treatment. Fourteen days later, the cub was re-evaluated at the OVAH. Clinical examination on presentation revealed that he was still underweight $(12.95 \mathrm{~kg})$ for his age, and bearing a small amount of weight on the right pelvic limb. He was sedated with a combination of $25 \mu \mathrm{g} / \mathrm{kg}$ medetomidine (Domitor, Pfizer Laboratories, Sandton, Gauteng, 2146, South Africa) and $4 \mathrm{mg} / \mathrm{kg}$ ketamine (Anaket-V, Bayer Animal Health Division, Isando, Gauteng, 1600, South Africa) mixed into a single syringe and injected intramuscularly. Follow-up radiographs revealed a substantial decrease in the amount of soft tissue swelling and maturely mineralised callus formation around the femoral fracture site. The fracture gap was still evident (Fig 2). Overall, there was an improvement in the radiographic bone density which was judged sufficient to allow internal fixation using advanced locking plate technology despite the evident osteopenia. The left ischial and right ilial fractures were almost completely healed by secondary bone healing. Continuation of the conservative treatment was debated at this stage but because of the risk of malunion or nonunion of the femoral fracture and the difficult logistics of managing a wild aggressive patient, the cub was admitted to theatre for surgical repair of the right femur. The anaesthetic management of the cub has been reported (Zeiler and others 2013).

The surgery was performed by the first author, a first year surgical resident at the OVAH. A standard lateral surgical approach to the femoral diaphysis was followed. The approach and identification of the muscle groups were challenging because of the extensive callus formation and disuse muscle atrophy.

A $2.5 \mathrm{~mm}$ intramedullary pin was placed in retrograde fashion to reduce the fracture before placement of the plate. The callus hampered manipulation and reduction of the fragments. The contouring of the 14 hole locking plate (string of pearls (SOP) plate; Orthomed UK Ltd, 70 Plover Road, Lindley,
FIG 1: Mediolateral right femur (a) and ventrodorsal pelvis $(\mathrm{b})$ radiographs revealing osteopenia, a comminuted pathological fracture of the proximal femoral diaphysis and pathological fractures of the right ilium and left ischium with collapse of the pelvic girdle
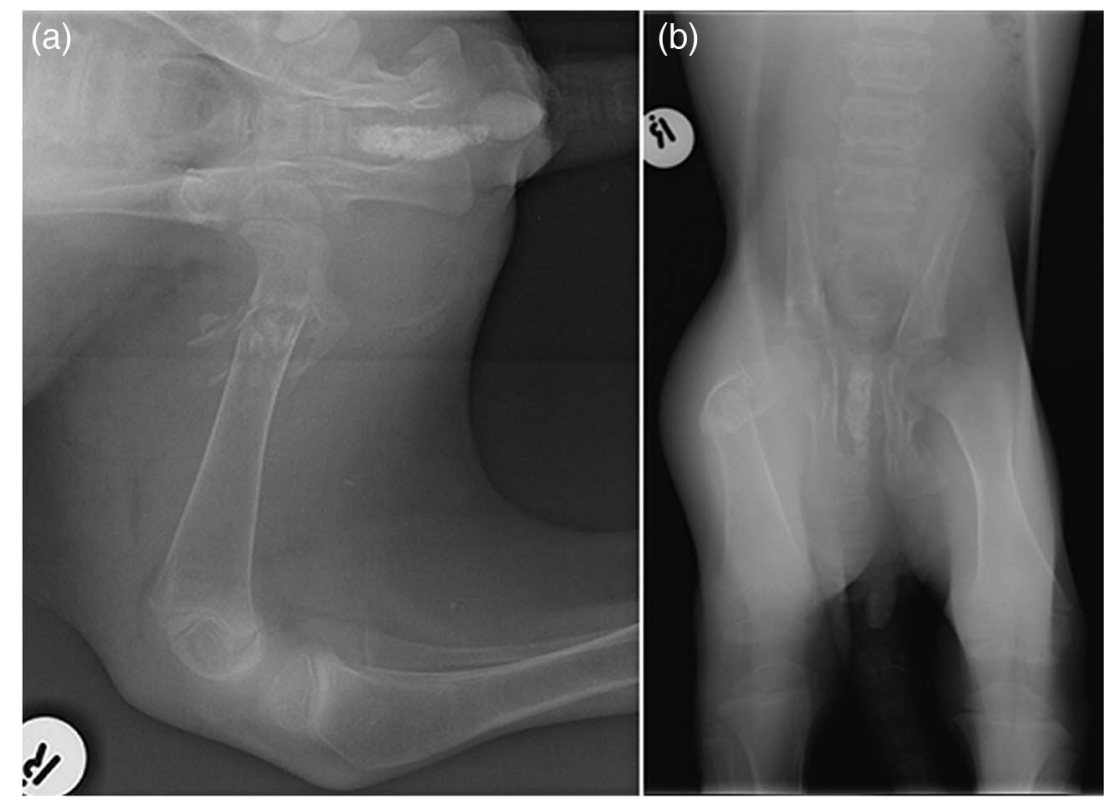
FIG 2: Craniocaudal (a) and mediolateral (b) radiographs of the right femur taken two weeks after medical treatment for secondary nutritional hyperparathyroidism was initiated. Maturely mineralised callus is evident around the fracture site. There is an overall radiographic improvement of the bone density although osteopenia is still evident
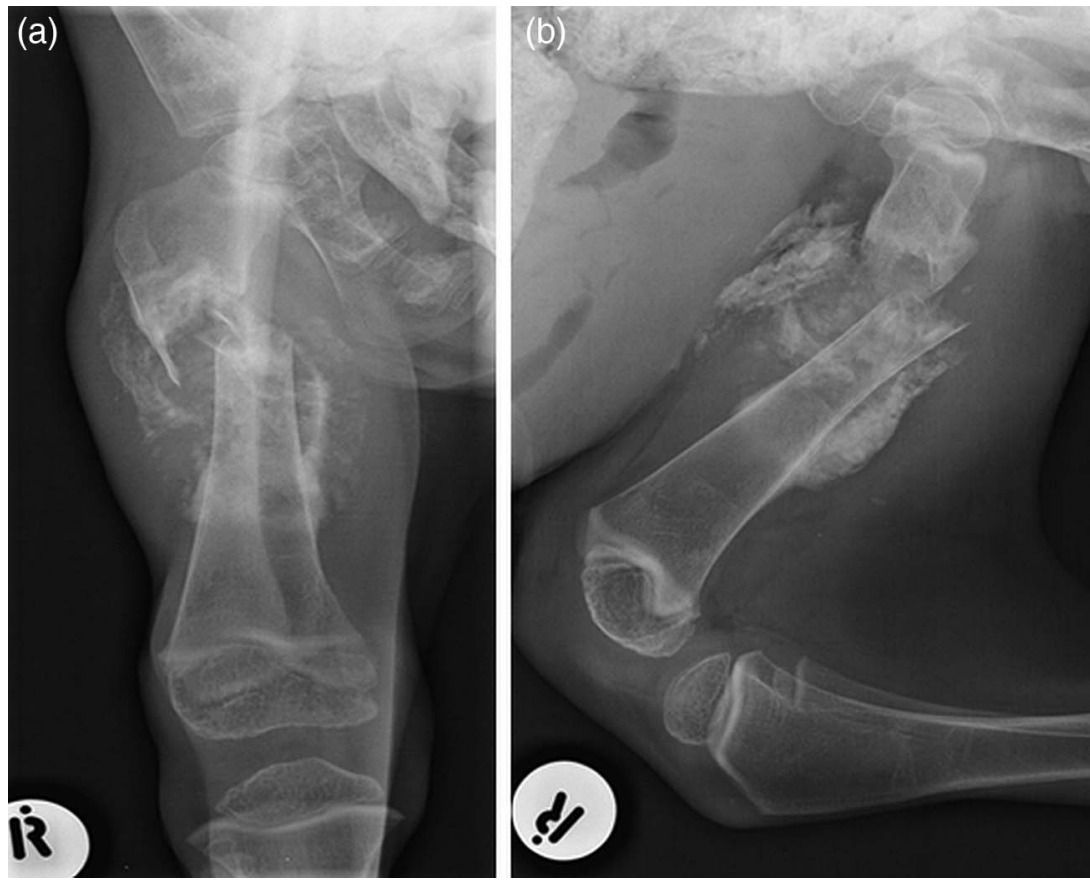

Huddersfield, West Yorkshire, HD3 3HR, UK) was demanding despite debulking the callus. One monocortical screw, placed at the base of the major trochanter, and four bicortical screws were placed in the proximal fragment and eight bicortical screws were placed in the distal fragment. The most distal screw hole was left open to avoid damage to the distal femoral growth plate by the placement of a cortical screw. The surgeon was unable to accurately identify the growth plate intraoperatively.

Postoperative radiographs revealed good fracture alignment, incorrect placement of the fifth proximal screw in the fracture line and an excessively long eighth transcortical screw extending into the soft callus and distant soft tissues (Fig 3). The distal part of the intramedullary pin penetrated the femoral epiphyseal cortex but clinically did not impede joint motion. The cub was hypothermic $\left(33.2^{\circ} \mathrm{C}\right)$, bradycardic $(48 \mathrm{bpm})$ and hypotensive (Doppler arterial blood pressure $50 \mathrm{~mm} \mathrm{Hg}$ ) during the anaesthetic period. Revision surgery was not a safe option due to the increased anaesthetic risk.

Recovery was delayed, yet uneventful before transporting him back to the NZGSA for further postoperative management.
FIG 3: Postoperative craniocaudal (a) and mediolateral (b) radiographs of the femur fracture repair of a tiger cub using a SOP plate-rod combination. latrogenic gas and mature callus is evident
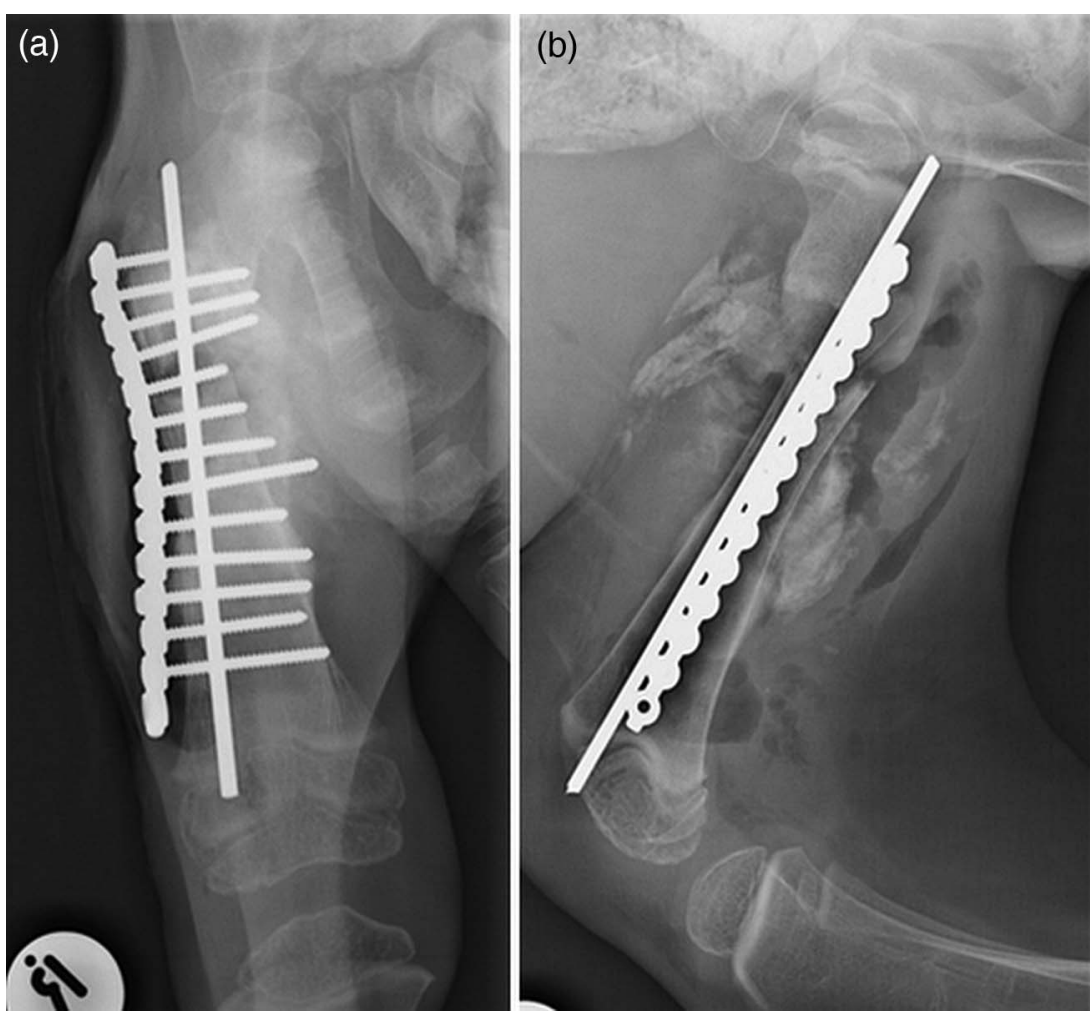
Postoperative analgesia was achieved with an epidural containing a $1.6 \mathrm{mg} / \mathrm{kg}$ long-acting ropivacaine (Naropin; AstraZeneca Pharmaceuticals, Johannesburg, South Africa) and $0.1 \mathrm{mg} / \mathrm{kg}$ morphine (Morphine Sulphate Fresenius PF; Intramed, Port Elizabeth, South Africa), as well as a single bolus of $0.2 \mathrm{mg} / \mathrm{kg}$ meloxicam with repeat doses administered according to behavioural changes and appetite. Based on the poor weight gain of the cub, its food was increased by 50 per cent after the surgery to approximately one and a half chickens per day. The supplemental calcium-multivitamin powder was, however, kept at $45 \mathrm{~g} /$ day. The cub still seemed lethargic and maintained a poor body condition score despite increasing its daily food intake. He was sedated with the same medetomidine/ketamine combination, a week after the surgery (day 22). He had not gained any weight since the surgery. He was also severely constipated, possibly due to a moderate degree of pelvic collapse. He was given approximately $600 \mathrm{ml}$ of warm Ringer's lactate intravenously and $200 \mathrm{ml}$ of warm water per rectum together with two vials of a laxative (Microlax, Pharmacia, North Ryde, New South Wales, 2113, Australia). In the following days, $10 \mathrm{ml}$ of liquid paraffin was added to the chicken. The chicken diet was also supplemented with several freshly killed feral pigeons and the whole carcase of a springbok (Antidorcas marsupialis) ewe that had died from traumatic injuries in the zoo. He started to gain weight rapidly and did not show any signs of constipation again when the liquid paraffin was discontinued after day 36 .

\section{OUTCOME AND FOLLOW-UP}

On day 63 , the cub was transported back to the OVAH for a follow-up examination and radiography. He now weighed $20.8 \mathrm{~kg}$. Radiographs revealed overall improved bone density, completely healed pelvic fractures and circumferential mature bridging callus across the femoral fracture site (Fig 4). The cub was discharged from the NZGSA on day 71. The owners were contacted telephonically on day 90 and day 300 for an update on the tiger's progress. They reported that the tiger continued to gain condition and develop normally, with no evidence of lameness or discomfort.

FIG 4: Follow-up mediolateral femoral (a) and ventrodorsal pelvic (b) radiographs taken 71 days after initial presentation revealing excellent secondary bone healing and callus formation of the femur fracture

\section{DISCUSSION}

Challenges over-and-above routine fracture management were encountered in a patient presenting with multiple fractures due to $\mathrm{NSH}$, namely severe osteopenia requiring effective medical management before surgical reduction of the femur fracture; appropriate selection of an implant to stabilise the fracture in osteopenic bone and the difficulty encountered during fracture repair due to the atrophied muscles and abundant mature callus formation obscuring the normal anatomy, resulting in two poorly placed cortical screws. The osteopenic and soft bone also resulted in the intramedullary pin penetrating the distal femoral cortex instead of seating within the medullary canal. The cortical penetration was not deemed clinically significant and was likely to have been beneath the articular cartilage surface.

Slusher and others (1965) were the first to report on the medical management of NSH in a tiger cub. Since then, sporadic reports of tigers suffering from NSH have been published over the years (Won and others 2004, Krook and Whalen 2010). These reports highlight the necessity to correct the dietary calcium:phosphorus ratio to approximately 2:1 during treatment and then 1:0.75 for daily maintenance requirements to resolve the metabolic bone disease (Ullrey and Bernard 1989). In most cases, dramatic clinical improvement can be achieved within 45 days of dietary management (Krook and Whalen 2010), as seen in this cub.

The pathological pelvic and greenstick long bone fractures in domestic and large felids are reported to resolve with dietary management and cage rest (Tomsa and others 1999, Krook and Whalen 2010). In this case, the cub sustained a complete femur fracture with displaced fracture fragments. The risk for a malunion or non-union was considered high without surgical intervention (Kumar and others 2007). The severe osteopenia, however, precluded immediate surgical stabilisation. Dietary management over 14 days was long enough to improve the bone density to allow fracture reduction using an advanced plate technology.

Several implants have been used alone or in combination for femoral diaphyseal repair in normal bone. External skeletal fixation, intramedullary pins and cerclage wires, interlocking nails
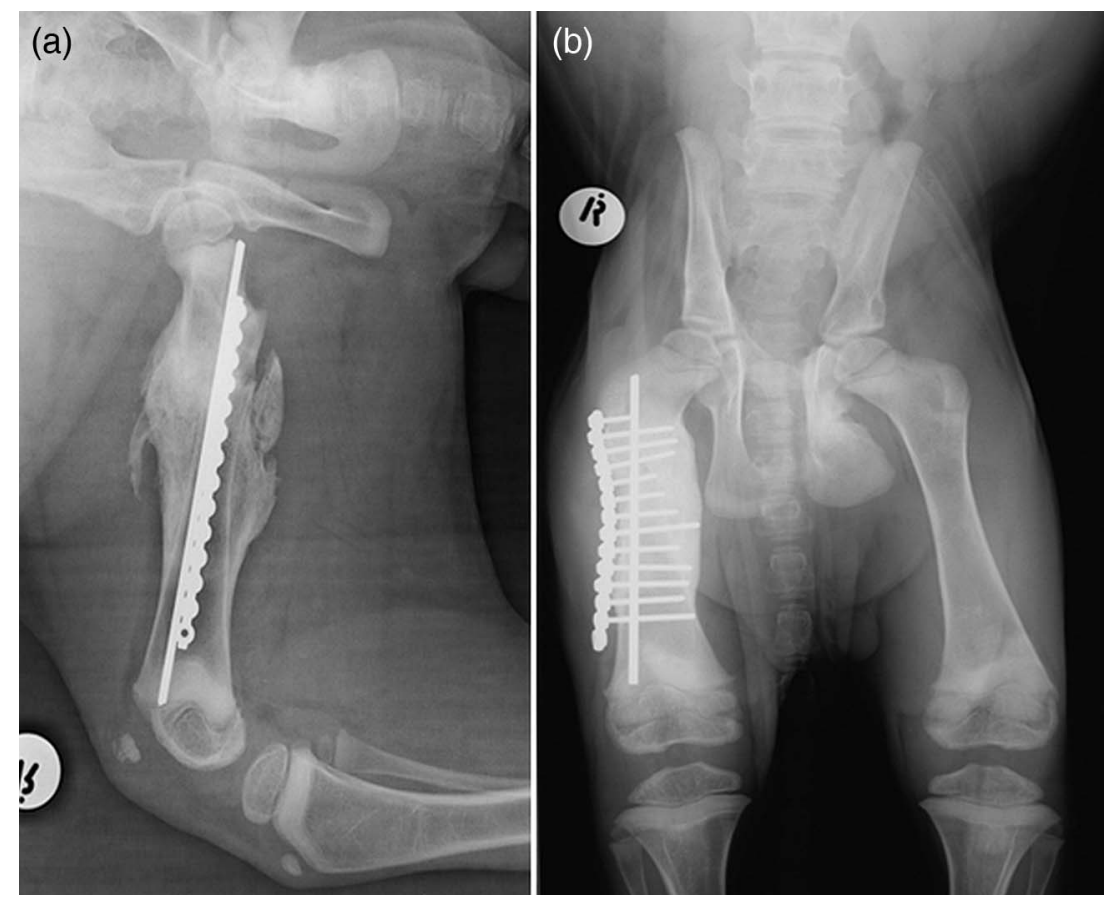
and bone plating have all been described (Simpson and Lewis 2002). The repair of femoral fractures has, however, been associated with a high incidence of complications in the past (Hunt and others 1980). These reported complications have highlighted the importance of implant selection in fracture repair. Aspects outside of the routine fracture repair faced in small animal practice, such as handling an aggressive patient, minimal postsurgical maintenance of wound care, excessive callus formation, poor cortical thickness, soft bone, atrophied muscles and the risk of muscle contracture had to be carefully considered before surgical repair.

The amount and density of bone are directly proportional to its strength (Ammann and Rizzoli 2003). On the basis of this relationship, several non-invasive imaging techniques have been developed to measure bone mineralisation at different skeletal sites. Among these, dual X-ray absorptiometry and CT have become established methods for evaluating skeletal status, assessing osteoporosis, determining fracture risk and the monitoring of metabolic diseases and therapies in human beings (Faulkner and others 1991, Grampp and others 1997). This application of dual X-ray absorptiometry and CT is still rare in veterinary science (Schneider and others 2004). These techniques, however, have the potential to become important research and clinical tools for the study of endocrine, nutritional and metabolic effects on bone mineralisation and bone healing (Schneider and others 2004). Dual X-ray absorptiometry was not available at the OVAH and the use of CT was declined by the owners due to financial constraints.

Regeneration of bone and enhancement of bone healing play a fundamental role in fracture management of animals with metabolic bone disease. The natural healing potential in these animals may be insufficient or the amount of bone that needs to be regenerated may be beyond normal physiological parameters. Different strategies and novel bone grafting techniques can be used to enhance or induce new bone formation (Kraus 2012). These strategies or materials must duplicate and amplify the events of secondary bone healing to achieve the desired result. The use of autologous bone graft is considered to be the gold standard as it possesses all the osteoconductive, osteoinductive and osteogenetic characteristics necessary for new bone growth (Ragetly and Griffon 2011). Autogenous bone grafts do, however, have several disadvantages. Harvesting of the graft would require an additional surgery at the donor site. Complications include pain, infection, blood loss, increased surgical time and pathological fracture at the donor site (Younger and Chapman 1989). A limited supply of cancellous graft in especially cats is also problematic (Ragetly and Griffon 2011). These limitations have necessitated the pursuit of alternatives. Researchers have developed several products using the criteria of a successful graft. Some of these novel products and techniques are already available for clinical use in animals, whereas others are still in the development stage (Ragetly and Griffon 2011). Bone morphogenetic proteins have recently received a lot of attention because of their potent ability to enhance osteoinduction and induce new bone formation. They stimulate angiogenesis and stem cell proliferation and facilitate the maturation of stem cells into chondrocytes, osteoblasts and osteocytes (Kirker-Head and others 2007). The use of bone morphogenetic proteins within the human and veterinary fields has shown promise in orthopaedic surgery (Vaibhav and others 2007). The benefits of using bone morphogenetic protein in this case are therefore clear but costs prohibited the application of this product. It was also decided not to perform an autogenous cancellous bone graft because of the potential risk of iatrogenic fracture at the donor site. Follow-up radiography two weeks after initiating the medical management of the NSH also revealed good callus and new bone formation and the start of the secondary bone healing process at the various fracture sites, which reduced the need for these osteoinductive options.

There are various studies of fracture repair in human patients with osteoporosis (Cornell 2003, Stromsoe and others 2004). These studies discuss the limited application of conventional implants for fracture fixation in osteoporotic bone. Fixation failures as a consequence of weak bone structure are highlighted. Major research efforts are being made to improve the current techniques and treatment options for the surgical repair of osteoporotic fractures in human beings (Kumar and others 2007). These findings are yet to be applied to veterinary patients.

Bone plating of the femur gained popularity in the early 1970s within the veterinary field (Johnston and others 2012). Over the years, different types of plates became available, including the most utilised dynamic compression plates, limited contact plates, reconstruction plates and more recently locking plates (Johnston and others 2012).

Conventional plates (dynamic compression, limited contact and reconstruction plates) create stability by compression of the plate to the bone creating friction (Egger 2008). The screws press the plate onto bone as the screw is tightened. The threads of the screw pull and slightly deform the bone that the threads engage (Kraus and Ness 2007). The success of the conventional plating systems relies on the screw purchase in the bone and the contact between bone and plate. Good-quality bone is therefore essential. The compression of the plate against the bone disrupts periosteal vascular supply and can retard healing of the underlying bone (Goh and others 2009). Where insufficient screw-to-bone fixation is available because of poor bone quality, cyclic loading of conventional plate-bone constructs can lead to secondary loss of fracture alignment and stability (Goh and others 2009). Screws are known to be susceptible to pull out fatigue in the metaphyseal region of bones where the cortex is thin, in osteoporotic bone, older patients, patients having slow bone healing conditions and patients that have poor compliance to restricted activity during the postoperative period (Beale 2007).

The most recent plating system available in veterinary surgery is the locking plate system (Beale 2007). The concept of a locking plate is that the screw 'locks' into the plate, instead of the screw pulling the bone towards the plate as in conventional plate technology. The advantages of locking plates over conventional plates are still being debated both in human and in veterinary medicine (Vezzoni 2011). Their use in several conditions has been proven to aid bone healing and provide quicker and more stable fixation (Vezzoni 2011). A SOP locking plate system in conjunction with an intramedullary pin was elected as the fixation method of choice in this case study. This construct provides superior fixation when compared with conventional plate constructs (Goh and others 2009). The use of an intramedullary pin enhances the stiffness of the construct and protects the plate against fatigue failure (Kraus and Ness 2007). It is the authors' opinion that this fracture could be treated with any of the locking plate systems available in the veterinary market. The SOP locking plate system was available in the OVAH. This system has the added advantage of being easy to contour in three planes.

By understanding some of the fundamental biomechanical differences between the traditional plating systems and the more recent locking plate systems, the authors' hope to highlight the importance of implant selection in this case study of treating an osteopenic long bone fracture. Advantages of the locking plate 
included: the rigid link between the screw head and the plate alleviated the need for the plate to be compressed against the bone and minimised disruption of periosteum and soft tissues (Goh and others 2009); the locking plate construct functioned as an internal fixator, thus precise anatomical contouring of the plate was not essential to maintain fracture alignment and stability (Goh and others 2009). This principle was particularly helpful in this case study because of the excess callus that had developed within the 14-day postinjury period, which would make accurate plate contouring a near impossible task.

The major disadvantage of the locking plate is that the 'feel' for good bone purchase is lost when placing the screws. This is because the screw head always makes good contact with the plate and gives the false sensation of good purchase. This became evident in this case when the fifth most proximal screw was placed through the callus and into the fracture line. It would have been immediately obvious that this screw did not have good bone purchase if the screw was tightened in a conventional plating system. The screw would not have seated well in the plate and would have 'stripped' as it was tightened, thereby confirming poor placement of the screw. Ideally, this screw should have been removed immediately postoperatively to reduce the risk of complications caused by implants within this area. Time pressures, increased anaesthetic risk and logistics did not allow for an immediate surgical revision to remove the poorly placed screw. Despite all efforts to correct the anaesthetic complications, the cub remained unresponsive to treatments and interventions. This was thought to be due to the poor body condition and inability to generate its own heat. The increased anaesthetic risk outweighed the option of immediate surgical revision. Despite being placed in this position, the risk for interference with bone healing was considered minimal because of the secure locking mechanism of the screw-plate interface, which would prevent screw movement or migration. It was also felt that there was some screw purchase in the mature callus. The callus also made the depth measurement of the drill holes more difficult. This resulted in one of the screws being excessively long. It is the authors' opinion that the advantages of dealing with better quality bone outweighed the technical difficulties associated with excessive callus formation.

Considering all the above biomechanical principles, a locking plate system was regarded as a better method of repair than that of conventional plating systems in this case. The authors' feel that the use of locking plate technology and the delay in surgical intervention were the key to a successful outcome of this patient. The advances in surgical plating systems mean that pathological fracture repair by locking plate internal fixation can be considered as a treatment option in osteopenic patients.

Contributors $\mathrm{CB}$ was the primary clinician and surgeon involved with this case and the person responsible for drafting the case report. GZ was involved with the anaesthesia of this patient and contributed to the drafting of the case report.

Competing interests None declared.

Provenance and peer review Not commissioned; externally peer reviewed.

\section{REFERENCES}

AMMANN P., RIZZOLI R. (2003) Bone strength and its determinants. Osteoporosis International 14, 13-18

BARR F. J. (2006) Long bones - juvenile. In BSAVA Manual of Canine and Feline Musculoskeletal Imaging. Eds F. J. Barr, R. M. Kirberger. Cheltenham: British Small Animal Veterinary Association. pp 19-31

BEALE B. (2007) Locking plates - simple, effective, and very sexy. Proceedings of the North American Veterinary Conference. Vol 21, Orlando, Florida, USA. pp 843-845 COETZEE R. (2011) Do exotic pets require permits? www.ewt.org.za (May 31, 2013)
CORNELL C. N. (2003) Internal fracture fixation in patients with osteoporosis. The Journal of the American Academy of Orthopaedic Surgeons 11, 109-119

DIMOPOULOU M., KIRPENSTEIJN J., NIELSEN D. H., BUELUND L., HANSEN M. S. (2010) Nutritional secondary hyperparathyroidism in two cats. Veterinary Comparative Orthopaedics and Traumatology 23, 56-61

EGGER E. (2008) Advantages of the locking plate. Proceedings of the North American Veterinary Conference. Vol 22, Orlando, Florida, USA. p 1014

FAULKNER K.G., GLUER C.C., MAJUMDAR S., LANG P., ENGELKE K., GENANT H.K. (1991) Noninvasive measurements of bone mass, structure, and strength: current methods and experimental techniques. American Journal of Roentgenology 157, 1229-1237

GOH C. S. S., SANTONI B. G., PUTTLITZ C. M., PALMER R. H. (2009) Comparison of the mechanical behaviors of semicontoured, locking plate-rod fixation and anatomically contoured, conventional plate-rod fixation applied to experimentally induced gap fractures in canine femora. American Journal of Veterinary Research 70, 23-29

GRAMPP S., GENANT H.K., MATHUR A., LANG P., JERGAS M., TAKADA M., GLUER C., LU Y., CHAVEZ M. (1997) Comparisons of noninvasive bone mineral measurements in assessing age-related loss, fracture discrimination, and diagnostic classification. Journal of Bone and Mineral Research 12, 697-711

HERZ V., KIRBERGER R. M. (2004) Nutritional secondary hyperparathyroidism in a white lion cub (Panthera leo), with concomitant radiographic double cortical line. Journal of the South African Veterinary Association 75, 49-53

HUNT J. M., AITKEN M. L., DENNY H. R., GIBBS C. (1980) The complications of diaphyseal fractures in dogs: a review of 100 cases. Journal of Small Animal Practice 21, 103-119

JOHNSTON S. A., VON PFEIL D. J. F., DEJARDIN L., WEH M., ROE S. (2012) Internal fracture fixation. In Veterinary Surgery Small Animal. Eds K. M. Tobias, S. A. Johnston. Missouri: Elsevier Saunders. pp 576-607

KIRKER-HEAD C.A., BOUDRIEAU R.J., KRAUS K.H. (2007) Use of bone morphogenetic proteins for augmentation of bone regeneration. Journal of the American Veterinary Medical Association 231, 1039-1055

KRAUS K. H. (2012) Bone grafts and substitutes. In Veterinary Surgery Small Animal. Eds K. M. Tobias, S. A. Johnston. Missouri: Elsevier Saunders. pp 676-684

KRAUS K. H., NESS M. G. (2007) Standard operating procedures for SOP fixation of fractures

KROOK L., WHALEN J. P. (2010) Nutritional secondary hyperparathyroidism in the animal kingdom report of two cases. Clinical Imaging 34, 458-461

KUMAR K., MOGHA I., AITHAL H., KINJAVDEKAR P., SINGH G., PAWDE A., KUSHWAHA R. (2007) Occurrence and pattern of long bone fractures in growing dogs with normal and osteopenic bones. Journal of Veterinary Medicine Series A 54, 484-490

LAMB C. R. (1990) The double cortical line - a sign of osteopenia. Journal of Small Animal Practice 31, 189-192

PEDERSON N. C. (1983) Nutritional secondary hyperparathyroidism in a cattery associated with feeding of a fad diet containing horsemeat. Feline Practice 13, 19-26

RAGETLY G., GRIFFON D. (2011) The rationale behind novel bone grafting techniques in small animals. Veterinary Comparative Orthopaedics and Traumatology 24, 1-8

ROBERTS G. (2004) Nutritional secondary hyperparathyroidism: a rare condition? Veterinary Times 34, 8-8

SCHNEIDER S., BREIT S.M., GRAMPP S., KUNSEL W.W., LIESEGANG A., MAYRHOFER E. ZENTEK J. (2004) Comparative assessment of bone mineral measurements obtained by use of dual-energy $\mathrm{x}$-ray absorptiometry, peripheral quantitative computed tomography, and chemical-physical analyses in femurs of juvenile and adult dogs. American Journal of Veterinary Research 65, 891-900

SIMPSON D. J., LEWIS D. D. (2002) Fractures of the femur. In Textbook of Small Animal Surgery. 3rd edn. Ed D. H. Slatter. Philadelphia: Saunders. pp 2059-2089

SLUSHER R., BISTNER S. I., KIRCHER C. (1965) Nutritional secondary hyperparathyroidism in a tiger. Journal of the American Veterinary Medical Association 147, 1109-1115

STROMSOE K. (2004) Fracture fixation problems in osteoporosis. Injury 35, 107-113

TOMSA K., GLAUS T., HAUSER B., FLÜCKIGER M., ARNOLD P., WESS G., REUSCH C. (1999) Nutritional secondary hyperparathyroidism in six cats. Journal of Small Animal Practice 40, 533-539

ULLREY D. E., BERNARD J. B. (1989) Meat diets for performing exotic cats. Journal of Zoo and Wildlife Medicine 20, 20-25

VAIBHAV B., NILESH P., VIKRAM S., ANSHUL C. (2007) Bone morphogenic protein and its application in trauma cases: a current concept update. Injury 38, 1227-1235

VEZZONI A. (2011) Fixing locking plates: a versatile system with numerous applications. Proceedings of the North American Veterinary Conference. Orlando, Florida, USA January 15 to 19,2011 . p. 1068

WON D. S., PARK C., IN Y. J., PARK H. M. (2004) A case of nutritional secondary hyperparathyroidism in a Siberian tiger cub. Journal of Veterinary Medical Science 66, 551-553

YOUNGER E.M., CHAPMAN M.W. (1989) Morbidity at bone graft donor sites. Journal of Orthopaedic Trauma 3, 192-195

ZEILER G. E., RIOJA E., BOUCHER C., TORDIFFE A. S. (2013) Anaesthetic management of two Bengal tiger (Panthera tigris tigris) cubs for fracture repair. Journal of the South African Veterinary Association 84, 1-5 